\title{
A renewed way of malaria control in Karnataka, South India
}

\section{Susanta K. Ghosh*, Satyanarayan Tiwari and Viajy P. Ojha}

Department of Biological Control, National Institute of Malaria Research, Bangalore, India

*Correspondence: ghoshnimr@gmail.com

\section{INTRODUCTION}

Malaria still causes a major public health problem in tropical and sub-tropical countries. Globally, World Health Organization (WHO) reports approximately 225 million malaria cases and 781,000 deaths each year, mostly in African children (WHO, 2010). In the past decade, several efforts have been initiated to scale-up malaria control, especially under Roll Back Malaria of WHO. Most of the interventions are indoor residual sprays (IRS), and use of insecticide treated nets (ITNs)/long-lasting impregnated nets (LLINs). This has resulted in significant reductions on malaria-associates morbidity and mortality in most parts of Africa. In spite of massive initiatives undertaken by various agencies, malaria still continues to haunt (O'Meara et al., 2010). Here, we describe how two larvivorous fish guppy (Poecilia reticulata) and mosquito fish Gambusia affinis are used in malaria control in villages in Karnataka, south India for more than a decade.

\section{MALARIA SITUATION IN INDIA}

National Vector Borne Disease Control Program (NVBDCP) is the central nodal agency, which takes care of all major vector borne diseases in India. Six diseases namely malaria, lymphatic filariasis, Japanese Encephalitis, kala-azar, dengue, and chikungunya are the major vector borne diseases in India [National Vector Borne Disease Control Program (NVBDCP), 2012]. Lymphatic filariasis and kala-azar are undergoing elimination process.

Currently, India contributes about $70 \%$ of malaria and $50 \%$ of mortality in the South East Asian Region of WHO. In most geographical settings, malaria transmission is heterogeneous having variable paradigms (Dash et al., 2008). It has witnessed several phases of malaria. In 1950s under the Global Malaria Eradication Program of WHO, malaria was almost reached at the eradication phase with the extensive use of DDT as the incidence declined from an estimated 75 million cases and 800,000 deaths in 1947 to a merely 49,151 cases in 1961 with no deaths. Recent trends show that each year India reports approximately two million malaria cases with 1000 deaths. Most of the cases are reported in the ethnic tribes living in the forested pockets of the states of Odisha, Jharkhand, Madhya Pradesh, Chhattisgarh and the North Eastern states which contribute bulk of morbidity and mortality (Dash et al., 2008).

Of the 10 known vectors, Anopheles culicifacies is the main rural vector mainly breeds in wells, streams and ponds, and responsible for $60-70 \%$ of rural malaria transmission. It has a complex of five sibling species designated as $\mathrm{A}, \mathrm{B}, \mathrm{C}, \mathrm{D}$, and $\mathrm{E}$. Anopheles fluviatilis, vector of local importance breeds in slow running streams and has four sibling species namely $S, T, U$, and $\mathrm{V}$. Species $\mathrm{S}$ is the main malaria vector in most of the tribal belts (Dash et al., 2008).

\section{STRATEGY FOR VECTOR CONTROL UNDER NATIONAL PROGRAM}

The main and effective control strategy to interrupt transmission is the use of synthetic insecticides such as organochlorine, organophosphate compounds, and synthetic pyrethroids applied under the national program guidelines. The major component of rural malaria control relies on IRS, whereas in the urban settings the main component is on larval control. Several chemical insecticides, insect growth regulator compounds, and also bio-pesticides such as Bacillus thuringiensis var. israelensis and B. sphaericus are being employed in vector control.

Insecticide method has not been very successful due to various factors of human behavior, resistance to vectors, operational, administrative, and prohibitive costs. Moreover, there are negative impacts on the non-target species. These are some of the reasons to go for other alternative methods of vector sanitation, draining, and environmental managements. In the national program, use of larvivorous fish has been advocated as an alternate strategy. A detailed description has given in the manual [National Vector Borne Disease Control Program (NVBDCP), 2009].

\section{LARVAL SOURCE MANNGEMENT}

Larval source management (LSM) in vector control has not got much importance due to various factors. The major reason was the lack of confidence in employing at the grass root level. In rural settings, besides scattered human settlements, there are vast breeding habitats of mosquitoes. In the beginning of the twentieth century, LSM was the only method of vector management, and got less importance after the arrival of DDT. It lasted for almost four decades, and it was realized the need of the alternate strategy when there was a resurgence of malaria in the mid 1970s. Even today LSM has received a low profile in vector management. Fillinger and Lindsay (2011) have given a detailed account on the use of this strategy, and pointed out that most of the developed nations are using this strategy to manage mosquito control. They questioned why this strategy has not got due importance in the African countries where the real problems exist.

\section{LARVIVOROUS FISH IN MALARIA CONTROL}

Among all the biocontrol agents, larvivorous fish are widely used in vector control. Approximately 315 fish species under seven genera are reported to have larvivorous nature (Ghosh and Dash, 2007). Two poeciliid fish P. reticulata and G. affinis are being used extensively. In India, fish are used in the public health program since 1903. In 1908, top minnow Poecilia a native of Caribbean Island was brought to British India for fishbased mosquito control. Another minnow Gambusia (generally known as mosquito fish) was introduced intentionally in most parts of the world out its native South America in 1905 (Gerberich, 1985).In 1928, Dr. B.A. Rao, brought this fish to India form Italy through sea route, and was released in the famous Lalbagh tank in Bangalore. This began the era of fish-based malaria control in India (Ghosh and Dash, 2007; Chandra et al., 2008).

\section{WHAT LED TO FISH INTRODUCTIONS IN KARNATAKA?}

Karnataka state produces $70 \%$ of high quality mulberry silk in India. District Kolar and adjoining areas produce major share of this 
variety of silk. Malaria was posing a serious public health problem in these areas, and the routine IRS for malaria control was hampering the rearing of the silk worms (Lepidopteran larvae). The local farmers thus resisted to such spray operations, and malaria control operation never got a local community support. Under such prevailing conditions, we took a challenge to control malaria without insecticide. Initially, we did not know how to solve such problem as there were no guidelines available for non-insecticide method of malaria control in rural settings.

To begin with, in 1993 one highly malaria problematic primary health center (PHC) Kamasamudram (population over 37,000) was selected as a demonstration site to evolve a non-insecticide method of malaria control. This PHC is situated $100 \mathrm{~km}$ east of Bangalore city. Entomological surveillance of vector species showed the presence of A. culicifacies and A. fluviatilis. After long deliberations, it was decided to undergo LSM against these vectors. Geographical reconnaissance was carried out to identify and locate the potential vector breeding habitats. Among various breeding sources, wells, ponds, and streams were the main breeding habitats of the two vector species. It was found that malaria was comparatively numerous in six sub-centers of this PHC. Interestingly, there were very less malaria in the remaining five sub-centers. This area is connected with the Kolar Gold Field which was operational from 1896. Further analysis of malaria distribution in the six sub-centers showed that villages having more number of malaria cases are surrounded by wells and ponds. On the contrary, villages located on streams had less number of malaria. Based on this information, genetic analysis of the vector species was carried out. Two sibling species A and $\mathrm{B}$ of $A$. culicifacies and, species $\mathrm{T}$ of A. fluviatilis were present. Species A was more numerous in villages having wells and ponds, whereas species B in villages located on streams (Ghosh et al., 2005). Based on laboratory experiments, species $\mathrm{A}$ is an efficient carrier of malaria parasites, while species B exhibited partial refractoriness to $P$. falciparum and complete refractoriness to $P$. vivax infections (Adak et al., 2006). All A. fluviatilis belonged to species T, and were zoophagic indicating non-participation in transmission (Ghosh et al., 2005).
This information was very important that helped in designing the LSM of the vector species. A pre-plan for channelization of the streams with a huge cost was thus abandoned (Ghosh et al., 2005).

Subsequent surveys in the non-malarious sub-centers detected the presence of Poecilia in most of the breeding habitats. Entomological surveillance also indicated the absence of the vector species. This was a great breakthrough in our search for planning a suitable vector control strategy. Accordingly, Poecilia was introduced in all the breeding habitats especially in ponds and wells in 1994. This resulted in almost $50 \%$ reduction on malaria incidence in 1995 from an average annual parasite index (API; cases per 1000 population per year) of over 40. Entomological surveillance and Poecilia monitoring indicated the ineffectiveness of this fish in ponds. In late 1995, approximately 500 Gambusia were released in a ditch connected with the main channel of Kamasamudram tank. In 1996 a heavy flood had occurred, and these fish were dispersed in the entire area along with the flood waters. Subsequently, this resulted in a total elimination of malaria in this area in the subsequent years for over 15 years. Entomological monitoring also showed very level of vector abundance that did not support malaria transmission.

In 2001, the trial was extended in a highly malaria-endemic area having a population of 1.3 million. Here the average API was over 130 and malaria has reached to a near elimination phase. Now, the program is being extended to the entire state.

\section{DISCUSSION}

Larvivorous fish in malaria control is a renewed strategy (Ghosh and Dash, 2007). In our study we have combined the use of two fish for better sustainability and effect on the vector population. Poecilia is very effective in closed eco-system mainly in wells, whereas Gambusia in open eco-systems namely ponds and streams. Another edible fish Grass carp Ctenopharyngodon idella, a large cyprind native of eastern Asia is useful in clearing aquatic weeds in ponds where mosquito larvae hide. Combination of C. idella with Gambusia effectively controlled larvae of $A$. culicifacies in village ponds that contained aquatic vegetations. C. idella cleaned the vegetations, and subsequently Gambusia eliminated the mosquito larvae. Thus malaria was eliminated in the affected villages (S. K. Ghosh, personal observation).

We have observed that Gambusia can be cultured along with other edible fish without any impact on the local fish fauna. Local fish species Puntius sp., Rasbora daniconius, Glossogobius giuris, Chanda nama, Channa sp. along with common edible carps were collected in Gambusia introduced ponds (S. K. Ghosh, personal observation). Haq et al. (1991) reported that Gambusia did not alter the edible fish production in village ponds in north India. They recommended both these fish can be cultured to get the dual benefits.

Fish-based malaria control is very cheap and sustainable. As per our estimate only INR 1.00 (US \$ 0.02) per capita per year is required for the entire operation. Kusumawathie et al. (2006) estimated application of $P$. reticulata was 2.67 times less costly than that of temephos (an organophosphorus anti-larval insecticide).

Several reports are now available on the use of fish in malaria control. In Somalia, Mohamed (2003) reported larval control in barkits (reservoirs) with Oreochromis spilurus spilurus. Fletcher et al. (1992, 1993) also mentioned the use of local fish Aphanius dispar and O. spilurus spilurus in Ethiopia. Matias and Adrias (2010) reported the effectiveness of Nothobranchius guentheri, a native of Tanzania, in temporary mosquito breeding habitats. This fish can be applied in arid zones where malaria vectors breed in temporary habitats.

There are some reports on negative impacts of the non-native poeciliid fish on the local fish fauna especially Gambusia (Rupp, 1996). However, we have not observed such impacts either on the local edible fish production or on the fish fauna. Work is underway to address this issue.

\section{CONCLUSION}

Our study has clearly shown that fish can be introduced in malaria control program. Poecilia introductions in indoor water storing cement tanks also contained Aedes aegypti larval infestation in Karnataka (Ghosh et al., 2011). This can be incorporated in the integrated vector management program (WHO, 1997). Use of global positioning systems and remote sensed data will enhance the progress of the fish-based malaria control program (Boswell et al., 2005). This work needs full 
dedication, and all potential breeding habitats must be covered with fish. Routine monitoring of fish survival and reintroduction are important for this strategy. Community participation and health education is an integral part of this strategy to achieve a malaria free world (Ghosh et al., 2006).

\section{ACKNOWLEDGMENTS}

The authors acknowledge the Indian Council of Medical Research, New Delhi for financial assistance. Partial assistance from WHO SEARO under RBM initiative is also acknowledged. The authors also thank the two anonymous reviewers for their critical comments and suggestions.

\section{REFERENCES}

Adak, T., Singh, O. P., Nanda, N., Sharma, V. P., and Subbarao, S. K. (2006). Isolation of a Plasmodium vivax refractory Anopheles culicifacies strain from India. Trop. Med. Int. Health 11, 197-203.

Boswell, E., Tiwari, S. N., and Ghosh, S. K. (2005). Feasibility of global positioning systems in mapping of mosquito breeding sites for the control of malaria vectors using larvivorous fish in Karnataka State, India. Trans. R. Soc. Trop. Med. Hyg. 99, 944.

Chandra, G., Bhattacharjee, I., Chatterjee, S. N., and Ghosh, A. (2008). Mosquito control by larvivorous fish. Indian J. Med. Res. 127, 13-27.

Dash, A. P., Valecha, N., Anvikar, A. R., and Kumar, A. (2008). Malaria in India: challenges and opportunities. J. Biosci. 33, 583-592.

Fillinger, U., and Lindsay, S. W. (2011). Larval source management for malaria control in Africa: myths and reality. Malar. J. 10, 353 .

Fletcher, M., Teklehaimanot, A., and Yemane, G. (1992). Control of mosquito larvae in the port city of Assab by an indigenous larvivorous fish, Aphanius dispar. Acta Trop. 52, 155-166.

Fletcher, M., Teklehaimanot, A., Yemane, G., Kassahun, A., Kidane, G., and Beyene, Y. (1993). Prospects for the use of larvivorous fish for malaria control in Ethiopia: search for indigenous species and evaluation of their feeding capacity for mosquito larvae. J. Trop. Med. Hyg. 96, 12-21.

Gerberich, J. B. (1985). Update of Annotated Bibliography of Papers Relating to Control of Mosquitoes by the Use of Fish for the Years 1965. Geneva: WHO.

Ghosh, S. K., and Dash, A. P. (2007). Larvivorous fish in malaria control: a new outlook. Trans. R. Soc. Trop. Med. Hyg. 101, 1063-1064.

Ghosh, S. K., Patil, R. R., Tiwari, S. N., and Dash, A. P. (2006). A community-based health education for bioenvironmental control of malaria through folk theatre (Kalajatha) in rural India. Malar. J. 5, 123.

Ghosh, S. K., Tiwari, S. N., Raghavendra, K., Sathyanarayan, T. S., and Dash, A. P. (2011). Observations on sporozoite detection in naturally infected sibling species of the Anopheles culicifacies complex and variant of Anopheles stephensi in India. J. Biosci. 33, 333-336.

Ghosh, S. K., Tiwari, S. N., Sathyanarayan, T. S., Sampath, T. R. R., Sharma, V. P., Nanda, N., Joshi, H., Adak, T., and Subbarao, S. K. (2005). Larvivorous fish in wells target the malaria vector sibling species of the Anopheles culicifacies complex in villages in Karnataka, India. Trans. R. Soc. Trop. Med. Hyg. 99, 101-105.

Haq, S., Prasad, H., and Prasad, R. N. (1991). Culture of Gambusia affinis with food fishes. Indian J. Malariol. 28, 201-206.

Kusumawathie, P. H., Wickremasinghe, A. R., Karunaweera, N. D., and Wijeyaratne, M. J. (2006). Larvivorous potential of fish species found in river bed pools below the major dams in Sri Lanka. J. Med. Entomol. 43, 79-82.

Matias, J. R., and Adrias, A. Q. (2010). The use of annual killifish in the biocontrol of the aquatic stages of mosquitoes in temporary bodies of fresh water; a potential new tool in vector control. Parasit. Vectors 3,46 .

Mohamed, A. A. (2003). Study of larvivorous fish for malaria vector control in Somalia, 2002. East. Mediterr. Health J. 9, 618-626.

National Vector Borne Disease Control Program (NVBDCP). (2009). Operational Manual for Implementation of Malaria Program. Directorate General of Health Services, Ministry of Health and Family Welfare, Government of India, 1-275. Available at: http://nvbdcp.gov.in/Doc/malariaoperational-manual-2009.pdf.

National Vector Borne Disease Control Program (NVBDCP). (2012). Vector Borne Diseases in India. Directorate General of Health Services, Ministry of Health and Family Welfare, Government of India. Available at: http://nvbdcp.gov.in/

O’Meara, W.P., Mangeni, J.N.,Steketee, R., and Greenwood, B. (2010). Changes in the burden of malaria in subSaharan Africa. Lancet Infect. Dis. 10, 545-555.

Rupp, H. R. (1996). Adverse assessments of Gambusia affinis: an alternate view for mosquito control practitioners. J. Am. Mosq. Control Assoc. 12, 155-166.

World Health Organization (WHO). (1997). Vector Control Methods for use by Individuals and Communities. Geneva.

World Health Organization (WHO). (2010). World Malaria Report: 2010. Geneva.

Received: 19March 2012; accepted: 22 May 2012; published online: 15 June 2012.

Citation: Ghosh SK, Tiwari S and Ojha VP (2012) A renewed way of malaria control in Karnataka, South India. Front. Physio. 3:194. doi: 10.3389/fphys.2012.00194

This article was submitted to Frontiers in Systems Biology, a specialty of Frontiers in Physiology.

Copyright $(2012$ Ghosh, Tiwariand Ojha. This is an openaccess article distributed under the terms of the Creative Commons Attribution Non Commercial License, which permits non-commercial use, distribution, and reproduction in other forums, provided the original authors and source are credited. 